afloramientos silíceos, pero entre los que predominan las areniscas rojas triásicas, las cuales parece rehuir en la zona esta especie, a lo que debe probablemente su gran rareza y el haber pasado hasta ahora inadvertida.

\title{
13. Adiciones a LA PTERIDOFLORA GaLlega
}

\author{
E. VALDES-BERMEJ0 (*) \& F.J. Silva-PANDO (**) \\ (*) Rúa de Castelao 6, Vilagarcía de Arousa. 36600-Pontevedra \\ (**) Departamento de Investigación Forestal de Lourizán \\ Xunta de Galicia. Ap. Correos 127. 36080-Pontevedra
}

\begin{abstract}
A continuación se señalan, para general conocimiento, varias citas que uno de los autores aportó, como asesor regional, al volumen I de FLORA IBERICA (1986) y que suponen en su mayoría novedad provincial, alguna de notable interés.
\end{abstract}

Equisetum hyemale L.

ORENSE: Humoso, Bibey, 29TPG66; s/f, Leg. B. Merino, LOU. s/n.

Polypodium interjectum Shivas

LA CORUÑA: Sta.. Uxía de Riveira, Ría de Arousa, Isla de Salvora, 29TNH9905, $10 \mathrm{~m}$, 5-IX-1982, sobre granodioritas, F.J. Silva-Pando 303 \& E. Valdés-Bermejo.

Notholaena marantae (L.) Desv.

LA CORUÑA: Santiso, Vilasoa, Ladera norte del embalse de Portodemuros-río Ulla, 29TNH7545, $260 \mathrm{~m}, 16-I V-1984$, en fisuras de rocas ultrabásicas, F.J.Silva-Pando 350 \& E. Valdés-Bermejo.

La población encontrada por nosotros creemos es la misma que la dada por Horjales (Anales Jard. Bot. Madrid 38:526, 1981) y que ésta sitúa en la provincia de Pontevedra. En caso contrario sería novedad provincial.

Pteris cretica L.

PONTEVEDRA: Pontevedra, Lourizán, 29TNG2795, 60 m, 7-II-1984, en paredes del palacia de Montero Ríos, A. Rigueiro \& F.J. Silva-Pando.

A. Rigueiro afirma haberla visto además en las murallas de Lugo.

Dryopteris aemula (Aiton) 0. Kuntze

PONTEVEDRA: Pontevedra, Lourizán, 29TNG2795, $60 \mathrm{~m}$, en lugares umbríos, F.J. Silva-Pando.

Esta cita confirma la de Ruiz de Azúa (Mem. R. Soc. Esp. Hist. Nat.XV:696, 1929) para Chapela-Vigo y puesta en duda por Dupont (La flora Atlant. Europeenne:109, 1962).

Polystichum aculeatum (L.) Roth

ORENSE: Humoso, 29TPG66, s/f, Leg. B. Merino, LOU-s/n 